\title{
Social Commerce Marketing Activities Participation Among University Level Students in Pakistan
}

\author{
Muhammad Irfan \\ PhD Scholar, Faculty of Management Sciences \\ Islamia college Peshawar \\ Irfan443@hotmail.com \\ Hamid Ullah \\ Assistant Professor, Faculty of Management Sciences \\ Islamia College Peshawar \\ Hamidullah@icp.edu.pk
}

\begin{abstract}
We live in the era of information communication society, where people are connected more than ever. Social media is becoming most trustable tool after word of mouth. The aim of this study was to examine participation of university level students in social marketing activities. The sample consisted of total 281 students, determined by circumstantial method. Questionnaire developed by the work of using the research of Korkmaz (2013), was used as data collection tools. Significant level was accepted as p<0.05 in statistical analysis. Independent t test, and structure equation modeling were used to assess the relationship among latent construct. Consequently, significant differences were found between genders in terms of "Trust" dimension, and "Source"( $p>0.05)$.
\end{abstract}

Key words: Social Commerce Marketing, Trust, Confidence

\section{Introduction}

The biggest story in business today is technology, plain and simple. Off course, there are some other big stories. Off shoring and globalization are also shaping strategy and structure both now and for some time to come, and are among one of leading key forces that shape market. Shifts in demographics are in ways that will cause deep and lasting changes in markets especially in developing countries with large population. However, technology is bigger, because recent progress in all things digital technology is removing constraints and creating exciting new possibilities that affect everyone's lives and enterprises. Social media let you to finally hear the voice of your customers and escape the narrow lenses of surveys and focus groups (Zaheer, 2018).Mobile computing makes that possible of all of your people to be available and productive no matter where they are. And significantly better forecasts, judgments, and decisions in key areas, are the promise of big data. However, the feeling is no being welcome for business organization due to fluctuation in $\$$ price, or other compliances barriers such as lack of digitalization skills of labor, inflation, so the overall business trend is likely to be slow and steady. There is much an upward pressure on wages. In order to survive in this unstable environment, companies face the challenge in retaining competent employee as of competing with other sectors also. This huge unbalance in needed skills and available labor make companies to focus on '5Ps' to overcome with the labor shortage national level. These five smart responses are:

1. Productivity 
2. Pricing

3. Participation

4. Package

5. Purpose

(KPMG, 2019)

On the other hand, e-commerce sector has 100 percent growth in year 2018, totaled 40.3 billion Rupees as compared to year 2017 sales which was recorded 28.8 billion rupees.according to consumer spending report of State Bank of Pakistan for the year 2018, the overall confidence level of consumer increased and cross the 50 points mark (highest recorded so far). According to Ali et al., (2019), in developing countries small and medium sized enterprises of are unable to adopt social commerce quickly. However, the adoption of e-commerce in Pakistan SMEs is a relatively novel phenomena form both perspective consumer and producers. Therefore one must understand before any further conclusion is this increase is due to; rise in income level or relatively low price, increase in education or cultural change, increase trust or changing preferences.

\section{Literature Review}

Wikipedia define social commerce (SC) as, the use of social network in the context of ecommerce transactions. According to Ali, et al., (2019), social commerce is novel stream and subset of e-commerce, with emerging online consumer. But social commerce adoption is still at its infancy stage in developing countries. However, it also provide opportunities for small business to compete with big organizations (Harris \& Dennis, 2002). Although there is no single consensus on definition of SC (Wang \& Zhang, 2012), some researcher like (Stephen and Toubia, 2010) argued that in SC the only thing matter is the direct interaction of consumer with business providers (Shen \& Eder, 2009). Literature shows social commerce as novel phenomena of extended way of business transaction with the advancement of internet and digital technology connectivity (Canavan et al., 2007) \& (Hajli, 2013) \& Beyari \& Abareshi, 2016). With the penetration smart phone and internet services across the communities across the globe with social networking the social commerce concept emerged (Yang etal., 2013). Which is originated back to 2005 when yahoo website provided a platform for social networking and shopping activities implement In social media, followed by Facebook the SC idea and named it F-commerce to facilitate business transactions (Wang \& Zhang, 2012). However, it also provide opportunities for small business to compete with big organizations (Harris \& Dennis, 2002).

Kim and Park, (2013), argued that consumer in social commerce might affect by some factor of trust, for instance transection security and company overall reputation. A good reputation can be create by business organization by providing high service quality (Park et al., 2012). However, as lack of face to face interaction, transaction security is playing main role in e-commerce as well as social commerce in emerging online business environment (Cheung and Lee, 2006 ), and (Teo \& Liu, 2007). Kim and Prabhakar (2000), argued that social commerce has impact on purchase intensions of consumers through social networks sites. However, at times the social marketing effort may actually be focused on keeping people from starting an undesirable behavior. In these cases, social marketing is seeking to influence behavior rather than to actually change it (Andreasen, 1994). For example, social marketing may be used to discourage teens from starting to smoke. In addition to these individual-level behavior influence efforts, social marketing efforts are increasingly being applied at the community or larger societal level, to change structures and practices that are detrimental to individual and societal well-being. 
In commercial marketing, for example, fast-food companies try to cater to consumer demand by opening more locations to be more convenient while also competing on price. Social marketing is the design, implementation, and control of programs calculated to influence the acceptability of social ideas and involving considerations of product planning, pricing, communication, distribution, and marketing research. (Kotler \& Zaltman, 1971). The use of social marketing has continued to grow both in practice and as a field of study in universities. With this, academic debates emerged over the appropriate boundaries for the field. Additionally, academics claimed that practitioners were not always applying the principles of social marketing appropriately, sometimes resulting in ineffective programs that wasted money, failed to provide the desired outcomes, and were hurting the reputation of the field (Andreasen, 1994), address these concerns, academic scholar Alan Andreasen proposed what was to become a very popular definition of social marketing:

"Social marketing is the adaptation of commercial marketing technologies to programs designed to influence the voluntary behavior of target audiences to improve their personal welfare and that of the society of which they are a part. (Andreasen, 1994, p. 110)".

Social marketing is the adaptation of commercial marketing technologies to programs designed to influence the voluntary behavior of target audiences to improve their personal welfare and that of the society of which they are a part (Andreasen, 1994, p. 110). This definition focuses our attention on influencing behavior, rather than other outcomes such as attitude change or increased knowledge. It also highlights the voluntary nature of the behaviors which social marketing addresses. Social marketing seeks to develop and integrate marketing concepts with other approaches to influence behaviors that benefit individuals and communities for the greater social good. Social marketing practice is guided by ethical principles. It seeks to integrate research, best practice, theory, audience and partnership insight, to inform the delivery of competition sensitive and segmented social programs that are effective, efficient, equitable, and sustainable (Morgan, 2012-2018).

Some researchers like (Liang et al., 2011), and (Hajli, 2013), who focused on purchase intension, and linked into customer satisfaction. In sum-up according to Ali, et al., (2019), adoption of social commerce can be categorized into individual factors, organizational factors, and technological factors. Some of previous studies like (Doney and Cannon, 1997, Gefen, 2000, Jones and Leonard, 2008), tested the effects of trust in online business. However, according to Kim and Park, (2013), gaining customer trust is challenging task for many online companies. Hajli, (2012), argued that consumer online purchase decision is affected by trust. While Kim et al., (2008), argued that trust play important role in consumer purchase intension (Gefen, 2000). Trust has been considered in literature as important matter in many different research fields like, for example economics (Beldad et al., 2010), psychology as transection safety (Das and Teng, 2004) and sociology (Kim and Park, 2013). However, there is lack of consensus as a concept on trust, as according to McKnight et al., 2002), researchers from different fields define it from different angle. For instance, Kim and Park, (2013), argued that consumer trust in social commerce might affect by transection security and company overall reputation. A good reputation can be create by business organization by providing high service quality (Park et al., 2012). However, due to lack of face to face interaction, transaction security is playing main role in e-commerce as well as social commerce in emerging online business environment (Cheung and Lee, 2006 ), and (Teo and Liu, 2007). While Kim and Prabhakar (2000), argued that social commerce has impact on purchase intensions of consumers through social networks sites. 


\section{Purpose of the study}

Millennials are reported to spend less on product and more on experiences, consumers are searching and learning in a very personalized way. While business organization should focus their marketing efforts by more addressing the changing need and satisfaction of the millennials. The very old marketing concept to know your store has changed into know your consumer with the advancement of technology and cyber world. Youth are the agent of any transformational change, and university students represent the important role in this change. Recent research shows after word of mouth social media is the most trustable source of marketing information among consumers (Pala, 2016).Therefore, the aim of this study is to examine participation of university level students in social commerce marketing activities.

\section{Hypotheses of the study}

The primary research question of the study was "are social commerce activities important for university student's level students? The following hypotheses have been formulated and tested to this end.

$\mathrm{H}_{1}$ : There is statically no significant difference in participating social commerce marketing activities between male and female students.

\section{Research methodology}

The detailed information of this study is represented in this section. It includes the study research model, data collection techniques, and analysis of collected data in detailed.

\section{Research model}

With the help of descriptive research model this study was conducted. In order to determine participation of university student in social commerce marketing activities in NUML University, Peshawar campus. Questionnaire was used, and related literature was revived and theoretical information was included.

\section{Population and sample}

The study population consisted of university students in NUML University, Peshawar campus and consisted of 188 (66.9\%) males, and 93 females (33.1\%); totally 281 students, (181 students in department of English and Languages, 100 students in departments of Management Sciences) took part in this study. 20-24 was mean ages of students.For selecting the sample, random sampling method was used. This sampling method based in which all members of group have independent and an equal chance of being selected (Arlı \& Nazik, 2004).

\section{Tool for data collection}

For collection of data survey method was adopted. By using the research of Korkmaz (2013), questionnaire was constituted for the study.Before applying the questionnaire, the validity and reliability analysis were done. After performing factor analyses the survey consisted of 3 subdimensions which were; Trust, Confidence, and Source. To test factor structure of the Questionnaire, factor analysis was applied. KMO (Kaiser-Mayer-Olkin) and Bartlett test were applied to find out the adequacy of the sample (Table 1). Suitability of data can be tested by using KMO and Bartlett tests, as Factor analysis cannot be suitable for all data. KMO value was found as 0.842 and Bartlett value was found as 3458.815 , and 0.000 was significant level. These findings prove that sample size and correlation between items are suitable.Cronbach's alpha 0.842 (Table 2)was found. The value of sub-dimensions internal consistencyin terms of validity and reliability was tested, and was found as for Trust 0.931, Confidence 0.874, and Source 
0.824(Table 3).Confirmatory factor analysis showed that Social commerce marketing activities Preference Questionnaire is suitable for the study. Perfect fit reported by modification indices (Figure 1).

\begin{tabular}{lcc}
\hline \multicolumn{2}{c}{ KMO measure of sampling adequacy } & $\mathbf{0 . 8 4 2}$ \\
\hline \multirow{2}{*}{ Bartlett's Test of Sphericity } & Chi-Square & 3348.550 \\
& df & 190 \\
& Sig. & $\mathbf{0 . 0 0 0}$ \\
\hline
\end{tabular}

Dimension

\begin{tabular}{lc} 
s & Cronbach Alfa \\
\hline Trust & 0.931 \\
Confidence & 0.874 \\
Source & 0.824 \\
\hline
\end{tabular}

Table 3. Social commerce marketing questionnaire confirmatory factor analysis.

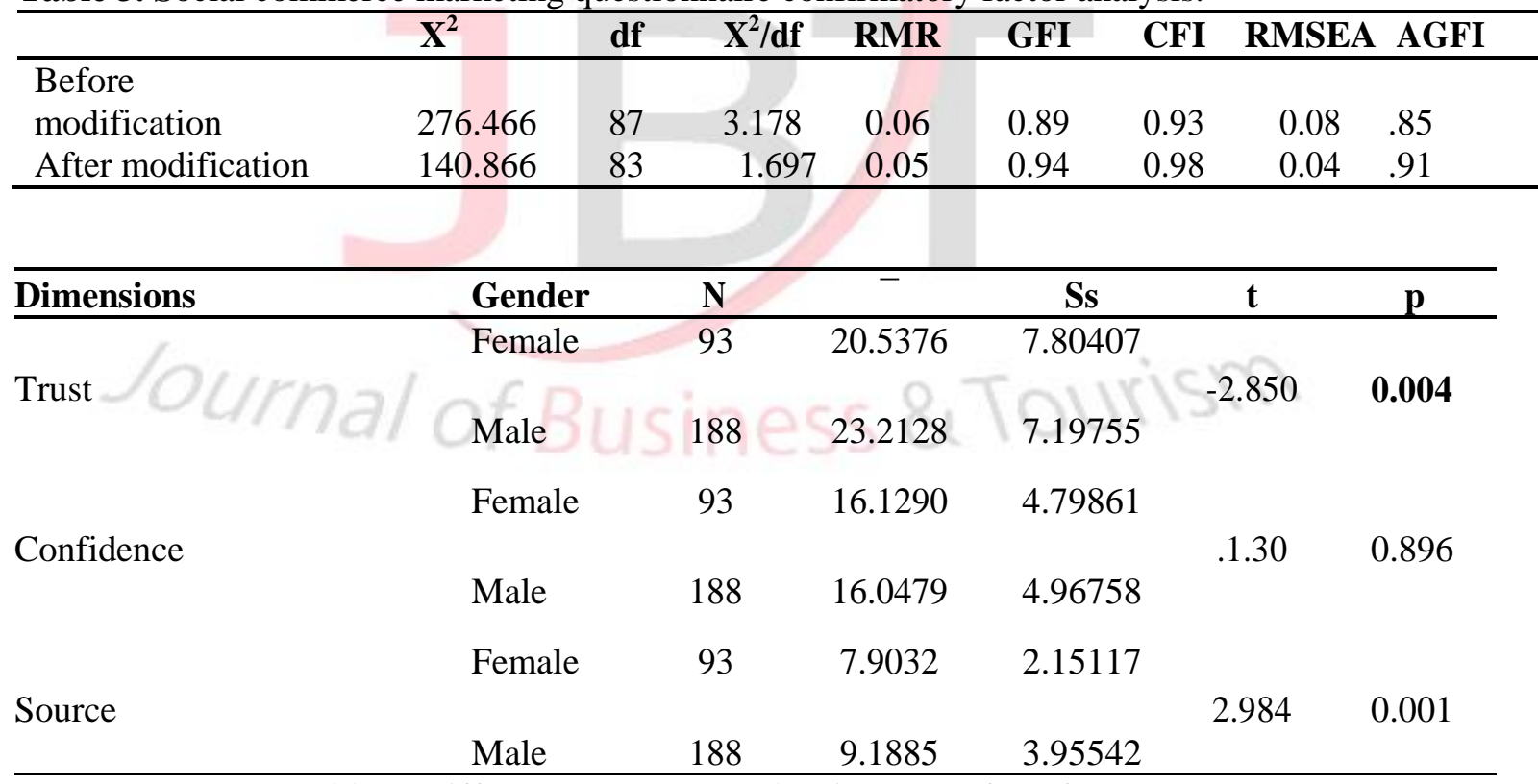

Table 5. Differences among genders in terms of preferences

Differences between genders in terms of social commerce marketing preferences are displayed in Table 5. In terms of genders significant differences were found between male and female students forTrust $(\mathrm{t}=-2.850, \mathrm{p}<.005)$ and Information Source $(\mathrm{t}=-2.984, \mathrm{p}<.005)$. Male students had higher mean recorded than females students in terms of sub-dimensions (Trust: $\mu_{\text {male }} 23.21$, sd $=7.19$, $\mu_{\text {female }}=20.53, \mathrm{sd}=7.80$ and Information Source: $\mu_{\text {male }}=9.18, \mathrm{sd}=3.95, \mu_{\mathrm{female}}=7.90, \mathrm{sd}=2.15$ ). In terms of Confidence no significant differences are found between genders. 


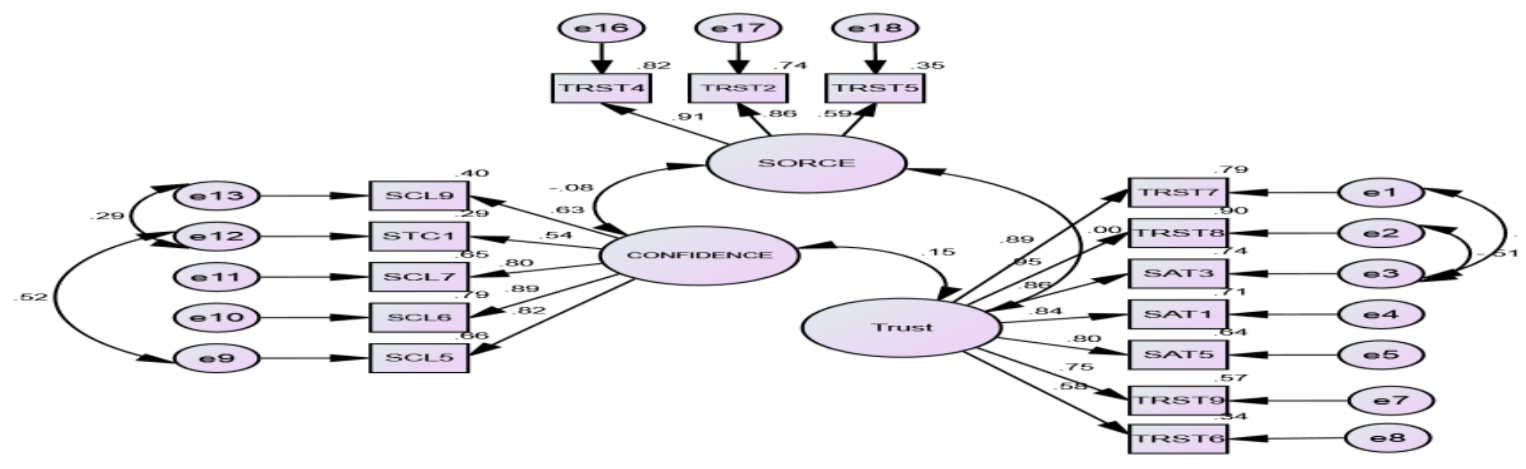

Figure 1. CFA of social commerce preferences questionnaire.

\section{Analysis of data}

Statistical package for social science (SPSS) Windows 22.0 software were used for data analysis. The sub-dimensions internal consistency were tested in terms of validity and reliability was found for Trust 0.931, Confidence 0.874, and Information Source 0.824. Frequency and percentage of the data were calculated, $\mathrm{KMO}$ and Bartlett test, and independent t test were performed.p $<0.05$ was accepted as significant level in statistical analysis. Through AMOS confirmatory factor analysis was applied.

\section{Findings}

Total 281 students, of which 93 females $(33.1 \%)$ and $188(66.9 \%)$ males, participated in the survey. Table 4 represents differences among gender in terms of social commerce marketing activities participation. In regards of Trust $(t=-2.850, p<0.05)$, and Information Source $(t=2.984$, $\mathrm{p}<0.05)$, significant differences were found among Male students and Female students. However, in term of Confidence level no significant difference are recorded (Table 4).

\section{Discussion}

As the sixth most populous country in the world, Pakistan is home to around 200 million people, with roughly half the population under the age of 29, an additional 2.1 million middle-income households are expected to be established by 2025 , and as the country continues to develop. Household consumption accounts for $\sim 80 \%$ of Pakistan's GDP and consumer spending is projected to grow at $\sim 15 \%$ in the coming years driven by the expanding middle class. Economic indicators suggest, Pakistan is an emerging economy projected to be among the fastest growing the coming years with a projected annual growth rate of $6 \%$ through to 2026 . According to Nielsen report (2019), Pakistan is now with the largest youth population, which is more techsavvy as compared to previous generation, have huge potential growth for e-commerce. Penetration of affordable smart mobile \& cheap 3G/4G internet service, subscriber growth has risen rapidly and 22 percent growth per year crossed 44 million mark in year 2016. Mobile user friendly app, the idea of owning less sharing more, changing life style, many more macro and micro level factors are contributing to its unpredictable potential growth. 
Facebook with more than three billion connections per day and above 17 billion user accounts leads social media (Zaheer, 2018). Twitter one the fastest growing preferred social media portal as more than 290 million connections per day. You tube, Instagram, are also in business. This increasing trust and convenience people see behind e-commerce platforms, are showing much improvement and growth in near future. According to statistics of State Bank of Pakistan, digital transections total online sale for fiscal year 2018 reached 40 billion, shows 100 percent growth, which were 20 billion for year 2017.

Online customers in Pakistan, search and purchased mostly for consumer electronics including mobile phones, employment queries, Sale/Purchase \& information gathering about vehicles, online education, counseling, leisure booking \& information seeking, other e-commerce services. There is no restriction to browsers Google chrome with 56 percent visitors of total no of visitors, and Internet Explorer to follow with 21 percent. While Android Safari, Opera Mini share the reaming percent searches. According to statistics of State Bank of Pakistan, digital transections total online sale for fiscal year 2018 reached 40 billion, shows 100 percent growth, which were 20 billion for year 2017. However, preferred payment still is cash-on-delivery.This result in increased liquidity requirements for company and also increased operational cost by dedicated sales team and cash receipts, record for company. Digital payment is one of the hurdle for ecommerce sector. Although various mobile banks products like, Jazz cash, uPaisa, Easy Paisa, are there today, but none of them have high market penetration. This can be justified by the fact that just 16 percent of country's total population has a bank account. Thus, e-commerce sector are bearing cost of doing business.

\section{References}

Adam, I., Hiamey, S., \& Afenyo, E. (2015). Leisure constraints in the university setting Ghana. Annals of Leisure Research, 18 (1), 145-158.

Ali, W., Mukhtar, M., \& Mohamed, I. (2019). The impact of technology, organizational, and trust factors on social commerce adoption. Journal of Theoretical and Applied Information Technology, 97 (21), 2908-2921.

Boyle, E. A., Connolly, T.M., Hainey, T., \& Boyle, J. M. (2012). Engagement in digital entertainment games: A systematic review. Computer in Human Behavior: 28, 771-780.

Chase, D. R., \& Cheek, N. H. (2018). Activity preferences and participation: Conclusions from a factor analytic study. Journal of Leisure Research, 11 (2), 135-142.

Ciochetto, L. (2015). The impact of new technologies on leisure activities in developed and emerging economies. International and Multidisciplinary Journal of Social Sciences, 4 (2), 194214.

Crawford, D., \& Godbey, G. (1987). Reconceptualizing barriers to family leisure. Leisure sciences, 9, 119-127.

Crawford, D., Jackson, E., \& Godbey, G. (1991). A hierarchical model of leisure constraints. Leisure studies, 13(4), 309-320, DOI: 10.1080/01490409109513147.

Dicle, O., \& Isil, S. (2010). Outdoor environment preferences in nursing homes: Case study of Ankara, Turkey. Scientific research and essays. 5, 3987-3993.

Doney, P. M. \& Cannon, J. P. (1997). An examination of the nature of trust in buyer-seller relationships. the Journal of Marketing, 35-51. 
Elizabeth, H. Weybright, Julie, S. Son \& Linda, L. Caldwell (2019). To have healthy leisure is to have balance: Young adult's conceptualization of healthy and unhealthy leisure. Journal of leisure research, doi: 10.1080/00222216.2019.1588694.

Godbey, G., \& Godbey, C. (2017). The future of leisure, tourism, and sport: Navigating change. United States: Venture Publishing Inc.

Granter, E. (2008). A dream of ease: Situating the future of work and leisure. Futures, 40, 803811.

Gershuny, J. (2002). Social leisure and home IT: A panel time-diary approach. IT \& Society, 1 (1), 54-72.

Hajli, M. (2012). Social Commerce: The Role of Trust. Eighteenth Americas Conference on Information Systems, Seattle, Washington, August 9-12, 2012., 1-11.

HAJLI, M. 2013. A research framework for social commerce adoption. Information Management \& Computer Security, 21, 144-154.

Lehto, X. Y., Park, O., Fu, X., \& Lee, G. (2014). Student's life stress and leisure participation. Annals of Leisure Research, 17 (2), 200-217.

Motamedi, M., Caldwell, L., weybright, E., jones, D. \& Wegner, L. (2019). Doing a leisure activity because there is nothing else to do: Related outcomes and intervention effects for adolescent. Journal of Leisure research. 8(86) p. 15.

Pala, A. (2016). Examining participation of university students in recreational entertainment marketing activities. Educational Research and Reviews, 11 (7), 339-344.

Przepiorka , A. M., \& Blachnio, A. P. (2017). The relationships between personality traits and leisure time activities: Development of the leisure time activity questionnaire (LTAQ). Neuropsychiatry, 7 (6), 1035-1046.

Sharaievska, I. (2017). Updating the family operating system: A literature review of information communication technology and family leisure. Leisure Sciences, 39 (5), 400-414.

Sharaievska, I., \& Stodoiska, M. (2017). Family satisfaction and social networking leisure. Leisure Studies, 36 (2), 231-243.

Sheykhi, M. (2004). Globalising influences on leisure: A university perspective from Iran. World Leisure Journal, 46 (4), 59-67.

Siu, R. (2018). Institutional change and the evolution of the world leisure industry. Journal of Economic Issues, 52 (2), 378-386. Doi:10.1080/00213624.2018.1463881.

Stebbins, R. A. (2010). Casual Leisure: A conceptual statement. Leisure Studies, 16 (1), 17-25.

Wang, C. \& Zhang, P. (2012). The Evolution of Social Commerce: The People, Management, Technology, and Information Dimensions. Communications of the Association for Information Systems, 31 . 